Linking Personality Trait Variance in Self-Managed Teams to Team Innovation

\author{
Sophie C. den Hartog ${ }^{1}$, J. Malte Runge ${ }^{1}$, Gudrun Reindl ${ }^{1}$, and Jonas W. B. Lang ${ }^{1,2}$ \\ ${ }^{1}$ Department of HRM, and Organizational Psychology, Ghent University, Ghent, Belgium \\ ${ }^{2}$ Business School, University of Exeter, UK
}

Corresponding Author:

Sophie C. den Hartog, Department of HRM, and Organizational Psychology, Ghent University, Henri Dunantlaan 2, 9000 Ghent, Belgium.

Email: SophieCharlotte.denHartog@UGent.be@ugent.be

Sophie C. den Hartog, J. Malte Runge, Gudrun Reindl, and Jonas W. B. Lang, Linking Personality Trait Variance in Self-Managed Teams to Team Innovation, 
Small Group Research. Copyright $\odot$ 2019. Reprinted by permission of SAGE Publications. https://journals.sagepub.com/doi/10.1177/1046496419865325 


\begin{abstract}
Researchers have suggested that some personality traits are associated with better team functioning when team members are homogeneous, whereas other personality traits improve team functioning when team members are heterogeneous. This article extends these ideas to team innovation and examines (a) how team variance in extraversion, agreeableness, openness, and conscientiousness relates to innovation in teams, and (b) how these relationships dynamically evolve over time. Our study included 704 surveys completed by 243 team members in 32 teams, at three time points. Results revealed that teams with less variance in extraversion showed higher levels of team innovation. For agreeableness and openness, we did not find main effects of team heterogeneity on team innovation. For teams with low heterogeneity in agreeableness, however, team innovation decreased over time. Team variance in conscientiousness was negatively associated with team innovation. Our findings provide support that team personality plays a role for innovation.
\end{abstract}

Keywords: Team composition, personality, innovation, growth model 


\section{Linking Personality Trait Variance in Self-Managed Teams to Team Innovation}

Teams are a vital part of modern organizations, and organizations seek to understand why some teams function well and others do not (Kozlowski \& Ilgen, 2006). One important characteristic of teams that has increasingly received attention in the research literature is the personality of its members (Barrick, Stewart, Neubert, \& Mount, 1998; Halfhill, Sundstrom, Lahner, Calderone, \& Nielsen, 2005). An influential theoretical idea on personality team composition is that not only the team average of a team personality trait is important, but also the degree of homogeneity/heterogeneity of the team members on that trait (Gonzalez-Mulé et al., 2014; Mohammed \& Angell, 2003). The underlying idea is that heterogeneity in a team leads to better team functioning for some personality characteristics because heterogeneity in personality characteristics creates varying approaches to do things and a broader range of team member behaviors that ultimately help the team (S. T. Bell, 2007; Humphrey, Hollenbeck, Meyer, \& Ilgen, 2007). For other team member characteristics, researchers have suggested that it is most useful for a team when team members are homogeneous, based on the idea that a uniform or strong climate in a group can lead to a more coherent unit that works better together (Bliese \& Britt, 2001; Schneider, Salvaggio, \& Subirats, 2002).

The aim of this article is to contribute to the literature on personality team composition by studying the effects of team personality variability on team innovation in a longitudinal study. Our study specifically advances research on team personality in two ways. First, we expand the criterion domain and focus on team innovation. Team innovation includes developing new ideas, adjusting to change, initiating change, and implementing new ideas and changes (Anderson, De Dreu, \& Nijstad, 2004; Anderson, Potočnik, \& Zhou, 2014). The innovation literature suggests that innovation is predicted by different personality predictors than performance (Potočnik, Anderson, \& Latorre, 2012). Building on this earlier work, we suggest that innovation in teams 
typically requires more intense direct and controversial team interaction. We propose that this need for additional social exchange makes it particularly likely that team innovation is affected by team personality composition.

Our second contribution is the fact that we do not only study static but also temporal change in the team personality composition/team innovation relationship. We specifically test the idea that team personality variability is more important in later stages of the lifecycle of a project team than in earlier stages. As Ployhart and Kim (2013) recently noted, a temporal perspective can provide novel insights as certain variables may only influence the outcome during certain stages of a longitudinal study. In line with this idea, there is initial evidence that effects of personality team composition only develop after a considerable amount of time has passed and team members have taken over specific work tasks and roles within the team (Stewart, Fulmer, \& Barrick, 2005). Adopting a temporal perspective is also in line with recent theoretical work on innovation suggesting that innovative behavior is not stable and typically dynamically changes over time (Chen, Bliese, \& Mathieu, 2005; van Knippenberg, 2017).

\section{Team Innovation}

Organizational researchers increasingly view innovation as essential and important for organizational long-term success (Anderson et al., 2004; van Knippenberg, 2017). A now widely adopted definition of innovation was suggested by West and Farr (1990) who described innovation as: "the intentional introduction and application within a role, group or organization of ideas, processes, products or procedures, new to the relevant unit of adoption, designed to significantly benefit the individual, the group, the organization or wider society" (p. 9). One important element of this definition is that an application component is necessary for innovation that goes beyond having new ideas. This application component makes innovation different from creativity that does not include the implementation of (new) ideas (Anderson et al., 2004). 
A second element of this definition is that it describes innovation in a broad context that can include more traditional innovation research focused on patents and products, but also entails innovation in procedures and processes (e.g., in the administration of organizations; Crossan \& Apaydin, 2010). In line with this part of the definition, a considerable number of studies has focused on innovations in organizational procedures and processes (e.g. Anderson et al., 2004; Welbourne, Johnson, \& Erez, 1998; Zacher \& Rosing, 2015). In this context, innovation has for instance been defined as perceptions of innovative effectiveness (Pearce \& Ensley, 2004) or described as a work role (Potočnik \& Anderson, 2016; West, 1987). In this study, we focused on the latter definition. The innovation-as-a-work-role conceptualization views innovation as a core part of the job requirements for most jobs that employees try to fulfill (West, 2002). An advantage of this conceptualization is that it generalizes across jobs and organizations and has been relatively well researched (Welbourne et al., 1998). For instance, one study has found that role-based innovation predicts whether employees suggest novel solutions over a period of one year and innovation-related individual bonus payments (Welbourne et al., 1998).

A third element of West and Farr's definition is that innovation can be conceptualized at different organizational levels. Most research on innovation focuses on the individual level, but researchers have suggested that innovation is equally or even more important at the team and organizational level (Potočnik \& Anderson, 2016; van Knippenberg, 2017). Organizational researchers have long suggested that findings from the individual level rarely generalize to the team level (Chen et al., 2005). Team-level innovation is particularly relevant because innovation and development work in organizations increasingly occurs in teams (Bantel \& Jackson, 1989; Ilgen, Hollenbeck, Johnson, \& Jundt, 2005; van Knippenberg, 2017). The motivation for the increasing use of teams in organizations is typically that teams make the use of diverse expertise possible because they can gather ideas of several diverse members, combine the information, and 
build on it jointly (Brown, Tumeo, Larey, \& Paulus, 1998). Yet, team work is not always successful and one potential reason is that the team members do not get along with each other because of personality differences (Hackman, 1998; Kozlowski \& Ilgen, 2006). A deeper understanding of personality predictors of successful innovation in team contexts could therefore be helpful for organizations. To our knowledge, there is no research that has systematically linked personality traits and variance in personality traits in teams to innovation in team environments. In the next section, we develop specific hypotheses on the relationship between team composition in personality and team innovation.

\section{Team Variance in Personality and Team Innovation}

Extent research on team composition has largely focused on team variability or dispersion and has operationalized team personality variability as the standard deviation of the personality trait in the team. This approach is not only in line with earlier work on team personality variability, but also with the broader organizational literature on group- and organization-level constructs (Chan, 1998; Schneider et al., 2002). In developing our hypotheses, we focused on four traits: extraversion, agreeableness, conscientiousness, and openness. Our focus on extraversion, agreeableness, and conscientiousness is because earlier theoretical (Humphrey et al., 2007) and empirical (Mohammed \& Angell, 2003) work on team variability has largely studied these traits and found some support of their relevance for team interactions. We also included openness because this trait is frequently discussed in the innovation literature (e.g., Baer \& Oldham, 2006; George \& Zhou, 2001; Madrid, Patterson, Birdi, Leiva, \& Kausel, 2014). We did not develop theoretical predictions for emotional stability, because earlier research did not suggest any relationships between team emotional stability and innovation (Mathisen, Martinsen, \& Einarsen, 2008). Earlier work also suggests that effects of team emotional stability typically only appear over long periods of time (Deuling, Denissen, van Zalk, Meeus, \& van Aken, 2011; 
Mathieu, Tannenbaum, Donsbach, \& Alliger, 2014) that exceed the six weeks covered in the present study.

\section{Team Extraversion Variance and Team Innovation}

Extraversion is typically interpreted as a personality trait that captures reactions to social situation; several researchers have suggested that extraversion is particularly relevant in team contexts (Barry \& Stewart, 1997; Mohammed \& Angell, 2004; Morgeson, Reider, \& Campion, 2005). One idea in the literature is that extraversion in teams will generally lead to a more positive atmosphere and better communication (S. T. Bell, Brown, Colaneri, \& Outland, 2018). However, extraversion is also a trait that entails social dominance (McCrae \& Costa, 1989). Based on the idea that extraversion includes dominance, researchers have suggested that heterogeneity in extraversion in self-managed teams may be beneficial for team functioning because a team with dominant and less dominant members may result in better task delegation and working through tasks efficiently (Humphrey et al., 2007; Mohammed \& Angell, 2003). While some researchers found that people feel more satisfied with the interaction if the interaction partner differs from them in terms of dominance (Sadler, Ethier, \& Woody, 2011; Shechtman \& Horowitz, 2006), other studies found that differences in team extraversion make social interactions more difficult in a dyadic or team context (Bono, Boles, Judge, \& Lauver, 2002; Cuperman \& Ickes, 2009). Researchers have studied this idea for performance as an outcome variable. However, findings in the literature on the team extraversion heterogeneity/performance relationship are somewhat mixed. A larger study with self-managed teams (Humphrey, Hollenbeck, Meyer, \& Ilgen, 2011) did not find effects of heterogeneity in extraversion on performance or team effectiveness. The meta-analysis by S.T. Bell (2007) showed a moderate effect of extraversion on performance, but the effects varied across samples. 
The theoretical arguments for team performance are likely to not generalize to team innovation. Communication and interaction are typically a crucial part of the team development process so that variance in extraversion likely has disadvantages for innovation in teams. Specifically, the tendency of the extraverted team members to talk more and dominate the conversation in the group (Humphrey et al., 2007) likely has negative consequences for team innovation. For instance, extraverted team members may share more ideas and introverted team members may stop talking altogether. As a result, opinions and perspectives of less extraverted team members may not be fully heard, and the team as a whole cannot profit from their perspectives and ideas. In addition, introverted team members may not buy into the new mission of the team because they do not really change their opinion. As a result, a silent conflict (Perlow \& Repenning, 2009) may develop in the team in the sense that introverted members disagree with group decisions but do not actively participate in group interactions. These ideas are in line with Cuperman and Ickes (2009) who found that similar levels of extraversion affect interaction in dyads positively. Research also suggests that team members are typically cautious to share radical and particularly innovative ideas in team contexts (see e.g., Asch, 1956; Janis, 1991) and a team with high extraversion variance may make this even less likely for the introverted members so that team innovation suffers. These ideas are in line with a study by Bono and colleagues (2002) who found that two-person teams with a higher difference in extraversion between the two members had more conflicts with each other. In summary, we suggest a negative relation between variance in extraversion in teams and team innovation.

H1a: Team variance in extraversion is negatively related to team innovation.

\section{Team Agreeableness Variance and Team Innovation}

Agreeableness is a personality trait that captures the degree to which individuals are perceived as kind, sympathetic, cooperative, warm, and considerate. People low in agreeableness 
are typically described as hard, unforgiving, and headstrong but also as more successful in advancing their ideas and opinions in organizations (Hunter \& Cushenbery, 2015). Team members who are low in agreeableness may be more willing to choose ideas that do not go along with usual social norms and will likely have the courage to enforce these new ideas in the group. This idea is also supported by a meta-analysis (Feist, 1998) showing that characteristics like hostility and arrogance are associated with more individual innovative achievement. Group members with low agreeableness are thus likely to be more successful in getting their ideas heard and making sure that their ideas are utilized by their group (Hunter \& Cushenbery, 2015).

At the team level, the effect of agreeableness and more specifically the role of team agreeableness variability is less clear. Baer, Oldham, Jacobsohn, and Hollingshead (2008) found no evidence for a relationship between agreeableness variability and creativity, and we are not aware of research examining the association between variance in agreeableness and team innovation. Nonetheless, high variability in agreeableness in a team may be helpful because less agreeable members of the team may push for innovative ideas and provide constructive criticism (Baer et al., 2008). More agreeable team members then may further discuss, accept, and actively work on these ideas (Paulus, 2000). Although this idea shares some similarities with theoretical ideas on extraversion, a fundamental difference between agreeableness and extraversion is that agreeableness is not related to the amount of communication in which team members engage. Instead, agreeableness mainly affects how strongly team members are voicing their own opinion and are willing to give in to a person who strongly voices his or her opinion. In summary, the empirical findings are limited but theoretical arguments and the existing literature on team agreeableness suggest that high variance in team agreeableness is positively associated with team innovation.

H1b: Team variance in agreeableness is positively related to team innovation. 


\section{Team Conscientiousness Variance and Team Innovation}

Conscientiousness is typically considered to be the most important personality predictor for task performance of individuals. It is less clear, however, how conscientiousness relates to innovative performance at the team level. As conscientious people typically think carefully before they make a decision and prefer well-thought out plans, they may be less likely to generate a large number of unusual and original ideas and may reject their ideas too quickly. In line with this notion, recent findings show that individual conscientiousness correlates negatively with individual creativity (Guo, Su, \& Zhang, 2017).

Researchers have argued that the negative effect of conscientiousness may translate to the team level so that more conscientious teams are less innovative (Baer et al., 2008), but researchers have also argued for taking the personality composition of teams into account when making predictions based on conscientiousness (S. T. Bell et al., 2018; Humphrey et al., 2007, 2011). One frequent observation shows that people with high conscientiousness generally dislike working with people low in conscientiousness because they feel that they need to shoulder all or most of the responsibility (S. T. Bell et al., 2018; Humphrey et al., 2007, 2011). Humphreys and colleagues (2007) have suggested that variance in conscientiousness is likely to generally hamper team functioning and increase team conflict. Their rationale is that differences in conscientiousness typically lead to different degrees to which employees set and adopt workrelated goals so that the goals of the team varying in conscientiousness will typically differ. These goal conflicts are likely to make an open exchange of ideas among team members less likely and is likely to make it harder for team members to build on each other's suggestions. We therefore expected that variance in conscientiousness is likely to be generally important for team functioning and should be negatively related to team innovation so that more homogeneous teams show higher levels of innovative behavior. 
H1c: Team variance in conscientiousness is negatively related to team innovation.

\section{Team Openness Variance and Team Innovation}

Openness may be relevant for innovation because openness also includes the willingness to consider new and unconventional ideas and being receptive to new views and perspectives (Costa \& McCrae, 1992). In line with these ideas, research has frequently found evidence for a positive relationship between openness and innovative behavior at the individual level (e.g. Baer \& Oldham, 2006; Hammond, Neff, Farr, Schwall, \& Zhao, 2011; Madrid et al., 2014). The research literature, however, suggests that results on the individual level cannot be generalized to the team level; thus, separate research is required targeting the team level to gain insights into effects of openness at the team level. Although a meta-analysis by S.T. Bell (2007) found small effects of variance in team openness on team performance, there are only few studies at the team level that focus on team innovation. The results of these studies are not consistent (Baer et al., 2008; Schilpzand et al., 2011). From a theoretical perspective, Reilly and colleagues (2002) have suggested that teams with radical innovative tasks will be more successful when the average of team openness is high. While this idea seems plausible, not all innovation work requires a radical approach, and the goal is frequently to improve upon an existing solution but not in an extreme way. Extreme levels of team openness may therefore also have disadvantages for teams because a group of highly open team members may come up with an extremely large number of ideas that are not really practically useful in the sense that they can be implemented. Furthermore, the presence of group members low in openness may actually lead to more refined ideas among the more open group members. Given that research on team openness composition is to our knowledge still very limited, we decided to investigate team openness composition and team innovation in the form of a research question.

RQ1: Is there a relation between team variance in openness and team innovation? 


\section{Team Temporal Dynamics}

Although researchers have long been aware that team processes (S. T. Bell \& Outland, 2017; Marks, Mathieu, \& Zaccaro, 2001; Tuckman, 1965) as well as outcomes of team work are dynamic and change over time (Weingart, 1997), most actual empirical research has long not fully taken this temporal nature into account in theorizing and by modeling change using data from multiple measurement occaisons (Bliese \& Ployhart, 2002; Ployhart \& Kim, 2013). Several researchers have therefore called for more theory and research on teams that takes temporal dynamics into account (e.g. B. G. Bell \& Cooke, 2003; S. T. Bell, 2007; Mathieu et al., 2014). Recently, team researchers have reacted to these calls by developing more theory on dynamic effects (Mathieu et al., 2014) and by conducting more longitudinal studies on team functioning (Cheng, Chua, Morris, \& Lee, 2012; Deuling et al., 2011; Harrison, Mohammed, McGrath, Florey, \& Vanderstoep, 2003).

An influential theoretical idea that links the temporal dynamics perspectives in team research to research on personality composition, is the notion that different types of team characteristics predict team functioning in early and later stages of a team's life cycle (Harrison et al., 2003; Price, Harrison, Gavin, \& Florey, 2002). Surface characteristics like demographic variables are important for team processes after the team is formed. Characteristics that describe the team composition on a deeper level such as personality, attitudes, or values, influence team processes and are then useful to predict team functioning in later stages of a team's life cycle (S. T. Bell \& Outland, 2017). The notion that team characteristics that predict team functioning change over time is also in line with research suggesting that working together in teams is a process that comes with changing challenges and tasks (e.g., S. T. Bell \& Outland, 2017; Marks et al., 2001; Tuckman, 1965). 
On the basis of the earlier empirical and theoretical work suggesting that deep-level/team functioning relationships are dynamic and typically become stronger over time $(\mathrm{S}$. T. Bell \& Outland, 2017; Lievens, Ones, \& Dilchert, 2009; Thoresen, Bliese, Bradley, \& Thoresen, 2004), it seems likely that effects of team personality variance — a deep level characteristic — on team innovation increase over time. Like other forms of team functioning, team innovation includes different tasks at different stages of a project and the change in the nature of these tasks may be particularly pronounced in team innovation. In the early stages of a team's functioning, the focus is typically on gathering ideas. In the initial stages of group development, the novelty and challenges of the new situation also leads to high task demands. Researchers have suggested that high task demands typically constrain the full expression of behaviors and personality (Lievens et al., 2009). As the time on the task progresses, other innovation behaviors - selecting ideas and implementing ideas_-become more relevant. Both tasks require more social interaction between the team members. We therefore suggest that personality characteristics focusing on interpersonal relationships like extraversion and agreeableness - also known as “getting along” personality characteristics (Hogan \& Holland, 2003) — should become more important for team innovation over time. In line with this idea, we assume two relationships:

H2a: The relationship between team variance in extraversion and team innovation becomes stronger over time.

$\mathrm{H} 2 \mathrm{~b}$ : The relationship between team variance in agreeableness and innovation becomes stronger over time.

Additionally, the variability in conscientiousness should become more relevant to team innovation. As explained earlier the goals of high vs. low conscientious team members differ in terms of effort that they want to invest or in how to organize tasks. We expect that highly conscientious team members likely develop the impression that less conscientious team mates do 
not engage themselves hard enough in the project. This friction likely becomes even stronger during the idea elaboration and implementation phase because this stage needs more coordination and effort compared to the idea gathering phase (West, Hirst, Richter, \& Shipton, 2004), and as a result hinder the innovation process increasingly over time.

$\mathrm{H} 2 \mathrm{c}$ : The relationship between team variance in conscientiousness and team innovation becomes stronger over time.

As outlined above, the role of team openness in team innovation is unclear; thus, we pose this relationship as research question. Since research has shown that deep level characteristics in general become more important over time, we assume that effects of variability in openness will also increase. During the idea gathering phase, team members focus on their task to find innovative ideas; in later stages, the team needs to choose between more innovative and more conservative options. Here the effect of variability in openness and conservatism should be more important than in the beginning. Therefore, we formulated a second research question for team openness.

RQ2: Does the relation between team openness variance and team innovation become stronger over time?

\section{Method}

\section{Participants and Procedure}

Participants were second year undergraduate university students participating in a mandatory eight week research course in psychology and were placed in teams based on topic preference at the beginning of the course. Students were not enrolled in other courses while in this course. Thus, the mark they received was an important part of their curriculum, and the task was achievable because it matched the requirements of their course. The assignment for each group was to do novel research and to write a report on it. They were free to choose one of the 
offered general topics and could then freely invent the research design of their own study. The team task thus did not have one correct solution and required that teams came up with ideas on how to design the research question, build hypotheses, collect data, write a scientific report, present their results, and how to organize their work flow. Thus, the group tasks included different and important aspects of innovation such as idea generation, idea selection, and idea implementation (Anderson et al., 2014; van Knippenberg, 2017). Hence, an important element in the course was for students to design their own study on the basis of their own ideas, but with the feedback of an expert in the particular field. Making innovation a core aspect of the assignment and therefore also a key part of the role that students needed to fulfill, in line with our innovationas-a-work-role conceptualization. There was no interdependence among the groups, as the groups worked independently, and also independently received feedback on their progress.

In total, 32 of the 41 teams in the course agreed to participate in this study. To estimate whether this is a sufficient sample size, we conducted an a priori-power analysis. Researchers commonly assume that typical individual-level effect sizes for personality variables are .30 (Thoresen et al., 2004) and use this in their power simulations. When one considers that the effect sizes in team research are somewhat larger, it is reasonable to expect effects around .40 for personality effects at the team level. We also assumed that interaction effects with time that are meaningful would be about half the overall effect size, meaning that the effect size would be 20 . Team research also typically has ICC1 values around .50 over time (teams measured multiple times). On the basis of these ideas, we conducted a power simulation using the procedures for power simulations commonly used in the literature (e.g., Mathieu, Aguinis, Culpepper, \& Chen, 2012). The R code for this power simulation is provided in Appendix A. Results showed that main effects have a power of .95 and interaction effects a power of .82 . 
The 32 teams in the final sample included a total of 243 team members (175 female and 86 male) with an average age of 21.69 years. Teams included 7.6 team members on average (range $=5$ to 9 ). Team members completed a questionnaire at three different points in time (Total sample size: $N=704$ ). The first survey took place at the beginning of the course project in week 1 (Time 1), the second survey was collected in the middle of the course project in week 3 (Time 2), and the third and final survey was collected near the end of the course project in week 6 (Time 3). By the time the teams filled out the week 1 survey they already had several meetings and were working together for at least a day because the format of the course required them to already hand in a broad outline of the goals of their research in the first week. All three questionnaires included questions on team functioning and the team innovation measure. The first questionnaire additionally included a personality inventory. The questionnaires were offered in Dutch, German, and English enabling participants to answer the questions in their native language.

\section{Measures}

Team Personality (T1). Participants worked on the Hexaco Personality Inventory 60 (Ashton \& Lee, 2009), a 60-item scale measuring six personality facets. The Hexaco personality is based on the HEXACO model which is a six-factor taxonomy modified from the five-factor model. The scales are conceptually largely identical to the corresponding factors in the five-factor model with the exception of the emotionality and the honesty-humility dimension (Ashton \& Lee, 2009; Ashton, Lee, \& Goldberg, 2004), which is not the focus of the current study. Each scale includes ten items. Participants responded using a 5-point Likert-type scale ranging from 1 (totally disagree) to 5 (totally agree). Cronbach's $\alpha$ for the extraversion, agreeableness, openness, and the conscientiousness scales were $.81, .74, .77$ and .80 , respectively.

Team Innovation (T1, T2, T3). Our study focused on role innovation in organizational procedures and processes as one operationalization of innovation measured at the group level. 
Similar to earlier research, we used ratings of innovation. One reason for the use of ratings in this research area is that the raters close to the process typically have a good insight into team innovation, especially when a quantitative count of innovations in the final product is difficult to achieve (as is the case for many work outcomes). Earlier research has typically used the team members themselves, peers, or the supervisor of a team (Anderson et al., 2004; Hülsheger, Anderson, \& Salgado, 2009) as a rater and then aggregated the shared perceptions to the group level. West and Anderson (1996) have reported high correlations between supervisor and team self-reports of innovation. This finding differs from typical findings in individual-level research where employee and supervisor ratings are frequently not highly correlated because the individual rating is affected by individual bias. In the context of multilevel research, potential individual-level biases are largely eliminated because of the aggregation to the group level (Bliese, 2000; Bliese \& Jex, 2002). We used a 4-item measure adapted from Welbourne and colleagues' (1998) role-based performance scale that researchers have frequently used to measure team innovation (Bono \& Judge, 2003; Chen, 2005; Chen, Sharma, Edinger, Shapiro, \& Farh, 2011; Zacher \& Rosing, 2015); it is similar to other work role based measures (Alban-Metcalfe \& Nicholson, 1984; West, 1987). We adapted the scale by reformulating the items from an individual-level referent (i.e., "I generate new ideas") to a team-level referent (i.e., "My team generates new ideas"). The use of a team-level referent is frequently recommended in the organizational literature because this approach is more in line with the nature of group-level constructs (Chan, 1998; West \& Anderson, 1996) and thus the goal of the present study. Participants responded to the questions using a 7-point Likert-type ranging from 1 (strongly disagree) to 7 (strongly agree). Cronbach's alpha was .86 at T1, .86 at T2, and .87 at T3. To evaluate whether it was justified to aggregate ratings of team performance to the team level, we 
estimated the intraclass correlation, type 1 (ICC1) and the $r_{w g(j)}$ statistic using a rectangular distribution (Bliese, 2000; Chan, 1998). Aggregation analyses revealed ICC1 values of ICC1 = .14 at $\mathrm{T} 1, \mathrm{ICC} 1=.08$ at $\mathrm{T} 2$, and $\mathrm{ICC} 1=.14$ at $\mathrm{T} 3$, and $r_{w g(j)}$ values of .86 at $\mathrm{T} 1, .84$ at $\mathrm{T} 2$, and .86 at T3. Recommendations in the literature typically suggest that aggregation is justified when ICC1 values and $r_{w g(j)}$ values exceed .10 and .70 , respectively.

\section{Analyses}

Our analyses were conducted at the team level and related team mean personality and team personality variance to team innovation. We first aggregated team mean personality and team innovation to the team level by taking the average of the ratings of all team members. One rationale for aggregation to the group level is typically also to eliminate individual differences in perception (Bliese, 2000). In line with previous research (Humphrey et al., 2011), we used the standard deviation in team member personality as our measure of team variability.

After aggregating our measures to the team level, we fitted multilevel mixed-effect growth models (Bliese \& Ployhart, 2002; Raudenbush \& Bryk, 1987) using the statistical environment R (R Core Team, 2015) and the nlme package (Pinheiro, Bates, DebRoy, Sarkar, \& Team, 2017). Multilevel mixed-effect growth models are a frequently used approach for modelling change because they are more flexible than traditional methods based on general linear models (Ployhart \& Vandenberg, 2010). Our models were two-level models with measurement occasions at level-1 nested in teams at level-2. The team personality measures were thus level-2 predictors that predicted the overall level (intercept) in the dependent variables, and changes (slopes) in the dependent variables over time. In all models, we did not only include the standard deviations in team personality traits that were part of our hypotheses, but we also included the respective team means. This strategy was chosen to ensure that potential findings regarding team 
personality would not result from a correlation with the team mean on the respective personality trait. The variance and the mean can be correlated (Humphrey et al., 2011). Another reason was that potential findings on the team mean in personality are also of interest. We specifically tested the following model:

$$
\begin{aligned}
& \text { Level-1: } Y_{j k}=\pi_{0 k}+\pi_{1 k} \mathrm{TIME}_{j}+e_{j k} \\
& \text { Level-2: } \pi_{0 k}=\gamma_{00}+\gamma_{01}(\text { EX } M)_{k}+\gamma_{02}(\text { EX } S D)_{k}+ \\
& \gamma_{03}(\mathrm{~A} M)_{k}+\gamma_{04}(\mathrm{~A} S D)_{k+} \\
& \gamma_{05}(\mathrm{O} M)_{k}+\gamma_{06}(\mathrm{O} S D)_{k^{+}}+ \\
& \gamma_{07}(\mathrm{C} M)_{k}+\gamma_{08}(\mathrm{C} S D)_{k}+u_{0 k} \\
& \pi_{1 k}=\gamma_{10}+\gamma_{11}(\operatorname{EX~} M)_{k}+\gamma_{12}(\text { EX SD })_{k}+ \\
& \gamma_{13}(\mathrm{~A} M)_{k}+\gamma_{14}(\mathrm{~A} S D)_{k+} \\
& \gamma_{15}(\mathrm{O} M)_{k}+\gamma_{16}(\mathrm{O} S D)_{k^{+}}+ \\
& \gamma_{17}(\mathrm{C} M)_{k}+\gamma_{18}(\mathrm{C} S D)_{k}+u_{0 k} \\
& e_{j k}^{i i d} \sim N\left(0, \sigma^{2}\right) \\
& \left(\begin{array}{l}
u_{0 k} \\
u_{0 k}
\end{array}\right) \underset{\sim N}{i i d} \quad\left(\left[\begin{array}{l}
0 \\
0
\end{array}\right],\left[\begin{array}{l}
\tau_{00} \tau_{01} \\
\tau_{01} \tau_{11}
\end{array}\right]\right)
\end{aligned}
$$

This model specifies that the response of team $k$ at measurement occasion $j$ is a function of general intercept $\gamma_{00}$, the time variable $\left(\mathrm{TIME}_{j}\right)$, the personality predictors $\left(\gamma_{01}\right.$ to $\left.\gamma_{08}\right)$, the interaction between the personality predictors and the time variable ( $\gamma_{11}$ to $\left.\gamma_{18}\right)$, a team random effect $u_{0 k}$, a team random slope $u_{1 k}$, and the residual variance $\mathrm{e}_{j k}$. Note that $\gamma_{02}, \gamma_{04}$, and $\gamma_{08}$, directly tested Hypothesis 1, 2, and 3, respectively. We centered the time variable at the second measurement occasion. This coding of time was convenient for the present study as the main effects of the personality composition predictors then refer to the effect of these variables midway through the study. To ease the interpretation of the analyses, we z-standardized the 
personality composition variables such that they were centered at the sample mean and had a standard deviation of 1 . We also estimated the model with z-standardized innovation ratings, so that the coefficients in this model $\left(\gamma_{s}\right)$ provide effect size information.

\section{Results}

\section{Descriptive Statistics and Correlations}

Table 1 presents the means, standard deviations and intercorrelations between the study variables. As shown in Table 1, the innovation measure at all three measurement occasions were correlated with each other but the correlations were not extremely high suggesting some change over time. These correlations were in the range typically observed for teams over time in the organizational literature (DeShon, Kozlowski, Schmidt, Milner, \& Wiechmann, 2004; Mathieu, Kukenberger, D’Innocenzo, \& Reilly, 2015; Mathieu \& Rapp, 2009).

\section{Growth Modelling}

Table 2 presents the multilevel growth models predicting team innovation over time. The results in Table 2 suggested that team mean personality did not have strong relationships with team innovation with the noteworthy exception of a significant effect of team mean extraversion, $\gamma=-0.13, t(32.00)=-2.28, p=.029$.

We next focused on effects of team variance in personality on team innovation and began by examining H1a. Recall that Hypothesis 1a predicted that group variance in extraversion would be negatively related to team innovation. As shown in Table 2, the extraversion intercept for team variance was significantly and negative related to team innovation, $\gamma=-0.22, t(32.00)=-4.18, p$ $<.001$. This finding is in line with our hypothesis for extraversion and shows that team heterogeneity in extraversion was negatively related to team innovation. H1b predicted that group variance in agreeableness would be positively related to team innovation. As shown in Table 2, variance in agreeableness was not significantly related to team innovation and the hypotheses is 
not supported. H1c suggested that group variance in conscientiousness would be negatively related to team innovation. As shown in Table 2, team variance in conscientiousness was significantly and negatively related to team innovation, $\gamma=-0.12, t(32.00)=-2.17, p=.037$; H1c was supported. The result shows, that heterogeneity in conscientiousness is negatively associated with team innovation.

RQ1 asked how group variance in openness to experience would be related to team innovation. As shown in Table 2, variance in openness to experience was not significantly related to team innovation.

In the last step, we analyzed whether or not the relationship between team variance in personality on team innovation changes over time. We began by examining $\mathrm{H} 2 \mathrm{a}$ that predicted that a negative relationship between team variance in extraversion and team innovation increases over time. We found that team variance in extraversion was significantly and negative related to the slope for team innovation, $\gamma=-0.11, t(65.70)=-3.28, p=.002$. To better understand the significant interaction between extraversion and time, we applied a simple slope analysis (Aiken \& West, 1991). The simple slope analysis revealed that team innovation decreased over time for groups with one standard deviation above the sample mean in extraversion, $t(63.65)=-4.50, p<$ .0001 ), and that team innovation did not change over time for groups with one standard deviation below the sample mean in extraversion, $t(63.65)=0.49, p=0.62)$. Figure 1 graphically illustrates this finding by plotting predicted values for teams that are one standard deviation above and one standard deviation below the sample mean in extraversion variability.

We then examined $\mathrm{H} 2 \mathrm{~b}$ that predicted that the positive relationship between group variance in agreeableness and team innovation increases over time. We found that team variance in agreeableness was significantly and positive related to the slope for team innovation $\gamma=0.07$ $\mathrm{t}(62.70)=2.15, \mathrm{p}=.035$. A simple slope analysis revealed that team innovation did not change 
over time for groups with one standard deviation above the sample mean in agreeableness, $t(63.65)=-0.46, p=0.65)$. Team innovation decreased over time for groups with one standard deviation below the sample mean in agreeableness, $t(63.65)=-3.75, p<.001)$. Figure 2 illustrates this trend, again for teams that are one standard deviation above and one standard deviation below the sample mean in agreeableness variability. Recall that we did not find a significant effect for the agreeableness variance as a predictor of team innovation (H1b). The significant slope effect, however, suggests that the effect of the agreeableness SD changed into the direction suggested by $\mathrm{H} 1 \mathrm{~b}$.

In $\mathrm{H} 2 \mathrm{c}$, we expected that the relationship between team variance in conscientiousness and team innovation becomes stronger over time. However, as shown in Table 2, variance in openness to experience was not significantly related the slope for team innovation, hence H1c was not supported.

In our second research question, we wanted to study whether a potential relationship between variability in team openness and team innovation would change over time. Table 2 shows, that variance in team openness to experience was not significantly related to the slope for team innovation.

\section{Supplementary Analyses}

In the supplementary analysis, we focused on the fact that extraversion includes two core subdimensions — sociability and dominance — and refitted the model separately with each of these two facets. Results revealed that both facets were related to the intercept for team innovation, sociability: $\gamma=-0.15, t(32.02)=-2.27, p=.03$; dominance: $\gamma=-0.20, t(32.00)=-3.34, p=.002$. However, only the effects of dominance became stronger over time, $\gamma=-0.11, t(61.67)=-3.31, p$ $=.002$. 


\section{Discussion}

Team researchers have suggested that variance in personality traits in teams is typically related to teams' functioning. In this article, we extended these ideas on team personality composition to team innovation and in addition examined temporal dynamics in the team personality variance/team innovation relationship. We found that teams which were more homogeneous in extraversion and conscientiousness had higher team innovation. For agreeableness and openness, there was no significant main effect for the relation between team heterogeneity and team innovation. However, for agreeableness we found that team innovation decreased over time for teams which were less heterogeneous. Our results also revealed that two of the four team personality variance/team innovation relationships that we studied became more pronounced over time. Specifically, the negative relation between team extraversion variance and team innovation became more negative over time, and the positive relation between team agreeableness variance and team innovation was more positive at the end than at the beginning of the study.

\section{Theoretical Implications}

Our study also extends earlier research on team personality composition by showing that personality/team innovation relationships dynamically change over time. Our study is one of the first studies, that we are aware of, that combines team personality with a growth model at the team level and thus follows these recent calls. Our finding that the team slope in team innovation was significantly predicted by team personality, suggests that a dynamic perspective could indeed provide a deeper understanding of the nature of team composition effects. Most notably, our findings largely support the notion (Stewart et al., 2005) that the role of team personality in team innovation becomes more important the longer a team works together. 
Our study also more broadly supports the idea that team personality and team personality composition predict team innovation and integrates earlier work on team composition (S. T. Bell, 2007; Humphrey et al., 2007; Mohammed \& Angell, 2003) with studies that link team personality and team innovation (Baer \& Oldham, 2006; George \& Zhou, 2001; Madrid et al., 2014). Our results partly support the theoretical idea that homogeneity of certain traits (like conscientiousness and extraversion) are beneficial in teams when teams need to work on tasks that require innovation (Humphrey et al., 2007). We found that both team homogeneity in conscientiousness and extraversion were associated with better team functioning. For team variance in conscientiousness, this result extends earlier findings and theorizing in the literature on team innovation, but was largely expected on the basis of theory and earlier research $(\mathrm{S}$. T. Bell, 2007; Humphrey et al., 2011).

As we noted earlier, research on the role of extraversion variance in teams has resulted in a mixed empirical picture. In the introduction of this paper, we focused on the specific nature of innovation work that differs from other team tasks (Potočnik et al., 2012). We reasoned that team member differences in extraversion will likely lead to less communication within the team, such as an introverted team member not speaking up and thus creating silent conflict. Therefore, we theoretically predicted a negative relationship between extraversion variance and team innovation. Our empirical findings provide support for this idea.

\section{Practical Implications}

Our study has several practical implications for team innovation. One practical implication is that not only the mean level but also the variance in personality is important for team functioning. In other words, team functioning depends on more than the sum of its parts. Organizations may use this information to make decisions on how to assemble innovative teams. 
A second practical implication of our study is that the nature of team work and the optimal configuration of a team may change over time. Organizations and practitioners may benefit as it provides insights into not only which teams are likely to run into innovation productivity problems but also when these types of issues are most likely to occur. For instance, our study suggests teams with high levels of extraversion variance increasingly underperform over time and organizations could especially target teams of this type with interventions such as team coaching.

More specifically, our results show that the effect of variance in agreeableness on innovation become more pronounced over time, in a way that more homogeneous teams had a decrease in innovation. The result suggests that heterogeneity in agreeableness is more important in the implementation phase of innovation rather than the idea generation phase. For teams higher in agreeableness it may be important to also have members that dare to stand up to convention, as innovation is often new and different. In teams lower in agreeableness, it may be important to have team members higher in agreeableness that solve possible conflicts to reach a consensus on how to implement a new procedure, also with the wider environment. This is in line with research that shows that the implementation phase requires different skills and motivators (Baer, 2012; Perry-Smith \& Mannucci, 2017).

\section{Limitations and Directions for Future Research}

A strength of our study is the longitudinal data from teams. A limitation of the study, however, is that all data was gathered from one source which can lead to common method bias (Podsakoff, MacKenzie, Lee, \& Podsakoff, 2003). Common method bias may be smaller in longitudinal designs (Podsakoff et al., 2003). Nevertheless, a multi-source longitudinal design would naturally be better than a longitudinal study with information from one source. Future 
research should study whether the findings of this study generalize to other contexts and other measurement approaches for innovation.

A second limitation is that it was conducted in an educational setting. The participants in our study were relatively young and included more female than male team members. The teams worked relatively closely together on their research task and the ultimate outcome was directly important for them. Results in other organizational settings may be different, for instance, when the majority of team members is male. These differences may reduce the generalizability of our results. However, the fact that we found evidence for our theoretical ideas in the context of a student sample does not necessarily mean that the effects do not exist in the real world. Outcomes for working teams such as promotions, raises, or keeping a job are more relevant than outcomes for student teams. The effects found in the present study can thus also potentially be even stronger in professional working teams. In line with ideas of this type, the S. T. Bell (2007) metaanalysis found that effects from lab settings were typically even stronger in field settings. An important goal for future research is to extend the present study by studying teams that perform other types of tasks and in other organizational settings.

\section{Conclusion}

Research suggests that modern work environments and markets change more quickly than in the past (World Bank, 2019). Studying and understanding team innovation may accordingly be even more important than in the past. The present study contributes to the team innovation literature by studying the effects of team personality composition on team innovation over time. Overall our findings support the idea that team homogeneity in extraversion and conscientiousness, as well as heterogeneity in team agreeableness, is associated with higher team innovation. Our study also suggest that team personality variance becomes more important over time for team innovation. 


\section{References}

Aiken, L. S., \& West, S. G. (1991). Multiple regression: Testing and interpreting interactions . Newbury Park, CA: Sage Publications.

Alban-Metcalfe, B., \& Nicholson, N. (1984). Career development of British managers. London, England: British Institute of Management.

Anderson, N., De Dreu, C. K. W., \& Nijstad, B. A. (2004). The routinization of innovation research: A constructively critical review of the state-of-the-science. Journal of Organizational Behavior, 25, 147-173. http://doi.org/10.1002/job.236

Anderson, N., Potočnik, K., \& Zhou, J. (2014). Innovation and creativity in organizations. Journal of Management, 40, 1297-1333. http://doi.org/10.1177/0149206314527128

Asch, S. E. (1956). Studies of independence and conformity: I. A minority of one against a unanimous majority. Psychological Monographs: General and Applied, 70, 1-70. http://doi.org/https://doi.org/10.1037/h0093718

Ashton, M. C., \& Lee, K. (2009). The HEXACO-60: A short measure of the major dimensions of personality. Journal of Personality Assessment, 91, 340-345. http://doi.org/10.1080/00223890902935878

Ashton, M. C., Lee, K., \& Goldberg, L. R. (2004). A hierarchical analysis of 1,710 English personality-descriptive adjectives. Journal of Personality and Social Psychology, 87, 707721. http://doi.org/10.1037/0022-3514.87.5.707

Baer, M. (2012). Putting creativity to work : the implementation of creative ideas in organizations. Academy of Management Journal, 55, 1102-1119. http://doi.org/10.5465/amj.2009.0470

Baer, M., \& Oldham, G. R. (2006). The curvilinear relation between experienced creative time pressure and creativity: Moderating effects of openness to experience and support for 
creativity. Journal of Applied Psychology, 91, 963-970. http://doi.org/10.1037/00219010.91 .4 .963

Baer, M., Oldham, G. R., Jacobsohn, G. C., \& Hollingshead, A. B. (2008). The personality composition of teams and creativity: The moderating role of team creative confidence. The Journal of Creative Behavior, 42, 255-282. http://doi.org/10.1002/j.21626057.2008.tb01299.x

Bantel, K. A., \& Jackson, S. E. (1989). Top management and innovations in banking: Does the composition of the top team make a difference? Strategic Management Journal, 10, 107124. http://doi.org/10.1002/smj.4250100709

Barrick, M. R., Stewart, G. L., Neubert, M. J., \& Mount, M. K. (1998). Relating member ability and personality to work-team processes and team effectiveness. Journal of Applied Psychology, 83, 377-391. http://doi.org/https://doi.org/10.1037//0021-9010.83.3.377

Barry, B., \& Stewart, G. L. (1997). Composition, process, and performance in self-managed groups: the role of personality. Journal of Applied Psychology, 82, 62-78. http://doi.org/https://doi.org/10.1037//0021-9010.82.1.62

Bell, B. G., \& Cooke, N. J. (2003). Cognitive ability correlates of performance on a team task. In Proceedings of the human factors and ergonomics society annual meeting (Vol. 47, pp. 1087-1091). Los Angeles, CA: SAGE Publication. http://doi.org/https://doi.org/10.1037/e576982012-009

Bell, S. T. (2007). Deep-level composition variables as predictors of team performance: A metaanalysis. Journal of Applied Psychology, 92, 595-615. http://doi.org/10.1037/00219010.92 .3 .595

Bell, S. T., Brown, S. G., Colaneri, A., \& Outland, N. (2018). Team composition and the ABCs of teamwork. American Psychologist, 73, 349-362. http://doi.org/10.1037/amp0000305 
Bell, S. T., \& Outland, N. (2017). Team composition over time. In E. Salas, W. B. Vessey, \& L. B. Landon (Eds.), Team dynamics over time (18th ed., pp. 3-27). Bingley, UK: Emerald Publishing. http://doi.org/10.1108/s1534-085620160000018001

Bliese, P. D. (2000). Within-group agreement, non-independence, and reliability: Implications for data aggregation and analysis. In K. J. Klein \& S. W. J. Kozlowski (Eds.), Multilevel theory, research, and methods in organizations: foundations, extensions, and new directions (pp. 349-381). San Francisco, CA: Jossey-Bass.

Bliese, P. D., \& Britt, T. W. (2001). Social support, group consensus and stressor-strain relationships: Social context matters. Journal of Organizational Behavior, 22, 425-436. http://doi.org/10.1002/job.95

Bliese, P. D., \& Jex, S. M. (2002). Incorporating a multilevel perspective into occupational stress research: Theoretical, methodological, and practical implications. Journal of Occupational Health Psychology, 7, 265-276. http://doi.org/10.1037/1076-8998.7.3.265

Bliese, P. D., \& Ployhart, R. E. (2002). Growth modeling using random coefficient models: Model building, testing, and illustrations. Organizational Research Methods, 5, 362-387. http://doi.org/https://doi.org/10.1177/109442802237116

Bono, J. E., Boles, T. L., Judge, T. A., \& Lauver, K. J. (2002). The role of personality in task and relationship conflict TL - 70. Journal of Personality, 70, 311-344. http://doi.org/10.1111/1467-6494.05007

Bono, J. E., \& Judge, T. A. (2003). Self-concordance at work: Toward understanding the motivational effects of transformational leaders. Academy of Management Journal, 46, 554571. http://doi.org/10.2307/30040649

Brown, V., Tumeo, M., Larey, T. S., \& Paulus, P. B. (1998). Modeling cognitive interactions during group brainstorming. Small Group Research, 29, 495-526. 
http://doi.org/10.1177/1046496498294005

Chan, D. (1998). Functional relations among constructs in the same content domain at different levels of analysis: A typology of composition models. Journal of Applied Psychology, 83, 234-246. http://doi.org/10.1037/0021-9010.83.2.234

Chen, G. (2005). Newcomer adaptation in teams: Multilevel antecedents and outcomes. Academy of Management Journal, 48, 101-116. http://doi.org/10.5465/AMJ.2005.15993147

Chen, G., Bliese, P. D., \& Mathieu, J. E. (2005). Conceptual framework and statistical procedures for delineating and testing multilevel theories of homology. Organizational Research Methods, 8, 375-409. http://doi.org/10.1177/1094428105280056

Chen, G., Sharma, P. N., Edinger, S. K., Shapiro, D. L., \& Farh, J. L. (2011). Motivating and demotivating forces in teams: Cross-level influences of empowering leadership and relationship conflict. Journal of Applied Psychology, 96, 541-557. http://doi.org/10.1037/a0021886

Cheng, C. Y., Chua, R. Y., Morris, M. W., \& Lee, L. (2012). Finding the right mix: How the composition of selfmanaging multicultural teams' cultural value orientation influences performance over time. Journal of Organizational Behavior, 33, 389-411. http://doi.org/10.1002/job.1777

Costa, P. T. ., \& McCrae, R. R. (1992). Revised NEO Personality Inventory (NEO-PIR): Professional Manual. Odessa, FL: Psychological Assessment Resources.

Crossan, M. M., \& Apaydin, M. (2010). A multi-dimensional framework of organizational innovation: A systematic review of the literature. Journal of Management Studies, 47, 11541191. http://doi.org/10.1111/j.1467-6486.2009.00880.x

Cuperman, R., \& Ickes, W. (2009). Big five predictors of behavior and perceptions in initial dyadic interactions: Personality similarity helps extraverts and introverts, but hurts 
“disagreeables.” Journal of Personality and Social Psychology, 97, 667-684. http://doi.org/10.1037/a0015741

DeShon, R. P., Kozlowski, S. W. J., Schmidt, A. M., Milner, K. R., \& Wiechmann, D. (2004). A multiple-goal, multilevel model of feedback effects on the regulation of individual and team performance. Journal of Applied Psychology, 89, 1035-1056. http://doi.org/10.1037/00219010.89.6.1035

Deuling, J. K., Denissen, J. J. A., van Zalk, M., Meeus, W., \& van Aken, M. (2011). Perceived influence in groups over time: How associations with personality and cognitive ability can change over time. Journal of Research in Personality, 45, 576-585. http://doi.org/10.1016/j.jrp.2011.07.005

Feist, G. J. (1998). A meta-analysis of personality in scientific and artistic creativity. Personality and Social Psychology Review, 2, 290-309. http://doi.org/10.1207/s15327957pspr0204_5

George, J. M., \& Zhou, J. (2001). When openness to experience and conscientiousness are related to creative behvior: An interactional approach. Journal of Applied Psychology, 86, 513-524. http://doi.org/10.1037/0021-9010.86.3.513

Gonzalez-Mulé, E., Degeest, D. S., Mccormick, B. W., Seong, J. Y., Brown, G., \& Brown, K. G. (2014). Can we get some cooperation around here? The mediating role of group norms on the relationship between team personality and individual helping behaviors. Journal of Applied Psychology, 99, 988-999. http://doi.org/10.1037/a0037278

Guo, J., Su, Q., \& Zhang, Q. (2017). Individual creativity during the ideation phase of product innovation: An interactional perspective. Creativity and Innovation Management, 26, 31-48. http://doi.org/10.1111/caim.12205

Hackman, J. R. (1998). Why teams don’t work. In R. S. Tindale, L. Heath, J. Edwards, E. J. Posavac, F. B. Bryant, Y. Suarez-Balcazar, \& J. Myers (Eds.), Theory and research on small 
groups. Social psychological applications to social issues (4th ed., pp. 245-267). New York, NY: Plenum Press.

Halfhill, T., Sundstrom, E., Lahner, J., Calderone, W., \& Nielsen, T. M. (2005). Group personality composition and group effectiveness an integrative review of empirical research. Small Group Research, 36, 83-105. http://doi.org/10.1177/1046496404268538

Hammond, M. M., Neff, N. L., Farr, J. L., Schwall, A. R., \& Zhao, X. (2011). Predictors of individual-level innovation at work: A meta-analysis. Psychology of Aesthetics, Creativity, and the Arts, 5, 90-105. http://doi.org/10.1037/a0018556

Harrison, D. A., Mohammed, S., McGrath, J. E., Florey, A. T., \& Vanderstoep, S. W. (2003). Time matters in team performance: Effects of member familiarity, entrainment, and task discontinuity on speed and quality. Personnel Psychology, 56, 633-669. http://doi.org/10.1111/j.1744-6570.2003.tb00753.x

Hogan, J., \& Holland, B. (2003). Using theory to evaluate personality and job-performance relations: A socioanalytic perspective. Journal of Applied Psychology, 88, 100-112. http://doi.org/10.1037/0021-9010.88.1.100

Hülsheger, U. R., Anderson, N., \& Salgado, J. F. (2009). Team-level predictors of innovation at work: A comprehensive meta-analysis spanning three decades of research. Journal of Applied Psychology, 94, 1128-1145. http://doi.org/10.1037/a0015978

Humphrey, S. E., Hollenbeck, J. R., Meyer, C. J., \& Ilgen, D. R. (2007). Trait configurations in self-managed teams: A conceptual examination of the use of seeding for maximizing and minimizing trait variance in teams. Journal of Applied Psychology, 92, 885-892. http://doi.org/10.1037/0021-9010.92.3.885

Humphrey, S. E., Hollenbeck, J. R., Meyer, C. J., \& Ilgen, D. R. (2011). Personality configurations in self-managed teams: A natural experiment on the effects of maximizing 
and minimizing variance in traits. Journal of Applied Social Psychology, 41, 1701-1732. http://doi.org/10.1111/j.1559-1816.2011.00778.x

Hunter, S. T., \& Cushenbery, L. (2015). Is being a jerk necessary for originality? Examining the role of disagreeableness in the sharing and utilization of original ideas. Journal of Business and Psychology, 30, 621-639. http://doi.org/10.1007/s10869-014-9386-1

Ilgen, D. R., Hollenbeck, J. R., Johnson, M., \& Jundt, D. (2005). Teams in organizations: From input-process-output models to IMOI models. Annual Review of Psychology, 56, 517-543. http://doi.org/10.1146/annurev.psych.56.091103.070250

Janis, I. (1991). Groupthink. In E. Griffin (Ed.), A first look at communication theory (pp. 235246). New York: McGraw Hill.

Kozlowski, S. W. J., \& Ilgen, D. R. (2006). Enhancing the effectiveness of work groups and teams. Psychological Science in the Public Interest, 7, 77-124. http://doi.org/10.1111/j.1529-1006.2006.00030.x

Lievens, F., Ones, D. S., \& Dilchert, S. (2009). Personality scale validities increase throughout medical school. Journal of Applied Psychology, 94, 1514-1535. http://doi.org/10.1037/a0016137

Madrid, H. P., Patterson, M. G., Birdi, K. S., Leiva, P. I., \& Kausel, E. E. (2014). The role of weekly high-activated positive mood, context, and personality in innovative work behavior: A multilevel and interactional model. Journal of Organizational Behavior, 35, 234-256. http://doi.org/10.1002/job.1867

Marks, M. A., Mathieu, J. E., \& Zaccaro, S. (2001). A temporally based framework and taxonomy of team processes. Academy of Management Review, 26, 356-376. http://doi.org/10.5465/AMR.2001.4845785

Mathieu, J. E., Aguinis, H., Culpepper, S. A., \& Chen, G. (2012). Understanding and estimating 
the power to detect cross-level interaction effects in multilevel modeling. Journal of Applied Psychology, 97, 951-966. http://doi.org/10.1037/a0028380

Mathieu, J. E., Kukenberger, M. R., D’Innocenzo, L., \& Reilly, G. (2015). Modeling reciprocal team cohesion-performance relationships, as impacted by shared leadership and members' competence. Journal of Applied Psychology, 100, 713-734. http://doi.org/10.1037/a0038898

Mathieu, J. E., \& Rapp, T. L. (2009). Laying the foundation for successful team performance trajectories: The roles of team charters and performance strategies. Journal of Applied Psychology, 94, 90-103. http://doi.org/10.1037/a0013257

Mathieu, J. E., Tannenbaum, S. I., Donsbach, J. S., \& Alliger, G. M. (2014). A review and integration of team composition models: Moving toward a dynamic and temporal framework. Journal of Management, 40, 130-160.

http://doi.org/10.1177/0149206313503014

Mathisen, G. E., Martinsen, Ø., \& Einarsen, S. (2008). The relationship between creative personality composition, innovative team climate, and team innovativeness: An input process - output perspective. Journal of Creative Behavior, 42, 13-31. http://doi.org/10.1002/j.2162-6057.2008.tb01078.x

McCrae, R. R., \& Costa, P. T. (1989). The structure of interpersonal traits: Wiggins's circumplex and the five-factor model. Journal of Personality and Social Psychology, 56, 586-595.

Mohammed, S., \& Angell, L. C. (2003). Personality heterogeneity in teams: Which differences make a difference for team performance? Small Group Research, 34, 651-677. http://doi.org/10.1177/1046496403257228

Mohammed, S., \& Angell, L. C. (2004). Surface- and deep-level diversity in workgroups: Examining the moderating effects of team orientation and team process on relationship conflict. Journal of Organizational Behavior, 25, 1015-1039. http://doi.org/10.1002/job.293 
Morgeson, F. P., Reider, M. H., \& Campion, M. A. (2005). Selecting individuals in team settings: The importance of social skills, personality characteristics, and teamwork knowledge. Personnel Psychology, 58, 583-611. http://doi.org/10.1111/j.1744-6570.2005.655.x

Nakagawa, S., \& Schielzeth, H. (2013). A general and simple method for obtaining R2 from generalized linear mixed-effects models. Methods in Ecology and Evolution, 4, 133-142. http://doi.org/10.1111/j.2041-210x.2012.00261.x

Paulus, P. (2000). Groups, teams, and creativity: The creative potential of idea-generating groups. Applied Psychology, 49, 237-262. http://doi.org/https://doi.org/10.1111/1464-0597.00013

Pearce, C. L., \& Ensley, M. D. (2004). A reciprocal and longitudinal investigation of the innovation process: The central role of shared vision in product and process innovation teams (PPITs). Journal of Organizational Behavior, 25, 259-278. http://doi.org/10.1002/job.235

Perlow, L. A., \& Repenning, N. P. (2009). The dynamics of silencing conflict. Research in Organizational Behavior, 29, 195-223. http://doi.org/doi:10.1016/j.riob.2009.06.007

Perry-Smith, J. E., \& Mannucci, U. (2017). From creativity to innovation : the social network drivers of the four phases of the idea journey, 42, 53-79. http://doi.org/10.5465/amr.2014.0462

Pinheiro, J., Bates, D., DebRoy, S., Sarkar, D., \& Team, R. C. (2017). nlme: Linear and nonlinear mixed effects models. R package version 3.1-131. Retrieved January 1, 2018, from https://cran.r-project.org/package=nlml

Ployhart, R. E., \& Kim, Y. (2013). Dynamic longitudinal growth modeling. In J. M. Ortina \& R. S. Landis (Eds.), Modern research methods for the study of behavior in organizations (pp. 63-98). New York: Routledge.

Ployhart, R. E., \& Vandenberg, R. J. (2010). Longitudinal research: The theory, design, and 
analysis of change. Journal of Management, 36, 94-120.

http://doi.org/10.1177/0149206309352110

Podsakoff, P. M., MacKenzie, S. B., Lee, J.-Y., \& Podsakoff, N. P. (2003). Common method biases in behavioral research: A critical review of the literature and recommended remedies. Journal of Applied Psychology, 88, 879-903. http://doi.org/10.1037/0021-9010.88.5.879

Potočnik, K., \& Anderson, N. (2016). A constructively critical review of change and innovationrelated concepts: towards conceptual and operational clarity. European Journal of Work and Organizational Psychology, 25(4), 481-494.

http://doi.org/10.1080/1359432X.2016.1176022

Potočnik, K., Anderson, N. R., \& Latorre, F. (2012). Selecting for innovation: Methods of assessment and the criterion problem. In J. K. Oostrom \& I. Nikolaou (Eds.), Employee recruitment, selection, and assessment: Contemporary issues for theory and practice (pp. 140). London: Psychology Press and Routledge Academic.

Price, K. H., Harrison, D. A., Gavin, J. H., \& Florey, A. T. (2002). Time, teams, and task performance: Changing effects of surface- and deep-level diversity on group functioning. Academy of Management Journal, 45, 1029-1045. http://doi.org/https://doi.org/10.2307/3069328

R Core Team. (2015). R: A language and environment for statistical computing. Vienna, Austria: R Foundation for Statistical Computing.

Raudenbush, W. S., \& Bryk, A. S. (1987). Examining correlates of diversity. Journal of Educational Statistics, 12, 241-269. http://doi.org/10.2307/1164686

Reilly, R. R., Lynn, G. S., \& Aronson, Z. H. (2002). The role of personality in new product development team performance. Journal of Engineering and Technology Management, 19, 39-58. http://doi.org/10.1016/S0923-4748(01)00045-5 
Sadler, P., Ethier, N., \& Woody, E. (2011). Interpersonal complementarity. In L. M. Horowitz \& S. Strack (Eds.), Handbook of interpersonal psychology: Theory, research, assessment, and therapeutic interventions (pp. 123-142). Hoboken, NJ: John Wiley \& Sons. http://doi.org/https://doi.org/10.1002/9781118001868

Schilpzand, M. C., Herold, D. M., \& Shalley, C. E. (2011). Members' openness to experience and teams' creative performance. Small Group Research, 42, 55-76. http://doi.org/10.1177/1046496410377509

Schneider, B., Salvaggio, A. N., \& Subirats, M. (2002). Climate strength: A new direction for climate research. Journal of Applied Psychology, 87, 220-229. http://doi.org/10.1037//00219010.87 .2 .220

Shechtman, N., \& Horowitz, L. M. (2006). Interpersonal and noninterpersonal interactions, interpersonal motives, and the effect of frustrated motives. Personality and Social Psychology Bulletin, 32, 1126-1139. http://doi.org/10.1177/0146167206288669

Somech, A., \& Drach-Zahavy, A. (2013). Translating team creativity to innovation implementation: The role of team composition and climate for innovation. Journal of Management, 39, 684-708. http://doi.org/10.1177/0149206310394187

Stewart, G. L., Fulmer, I. S., \& Barrick, M. R. (2005). An exploration of member roles as a multilevel liking mechanism for individual traits and team outcomes. Personnel Psychology, 58, 343-365. http://doi.org/https://doi.org/10.1111/j.1744-6570.2005.00480.x

Thoresen, C. J., Bliese, P. D., Bradley, J. C., \& Thoresen, J. D. (2004). The big five personality traits and individual job performance growth trajectories in maintenance and transitional job stages. Journal of Applied Psychology, 89, 835-853. http://doi.org/10.1037/00219010.89 .5 .835

Tuckman, B. W. (1965). Developmental sequence in small groups. Psychological Bulletin, 63, 
384-399. http://doi.org/https://doi.org/10.1037/h0022100

van Knippenberg, D. (2017). Team innovation. Annual Review of Organizational Psychology and Organizational Behavior, 4, 211-233. http://doi.org/10.1146/annurev-orgpsych-032516113240

Weingart, L. R. (1997). How did they do that? The ways and means of studying group processes. Research in Organizational Behavior, 19, 189-240.

Welbourne, T. M., Johnson, D. E., \& Erez, A. (1998). The role-based performance scale: Validity analysis of a theory-based measure. Academy of Management Journal, 41, 540-555. http://doi.org/10.2307/256941

West, M. A. (1987). Role innovation in the world of work. British Journal of Social Psychology, 26, 305-315. http://doi.org/10.1111/j.2044-8309.1987.tb00793.x

West, M. A. (2002). Sparkling fountains or stagnant ponds : An integrative model of creativity and innovation implementation in work groups. Applied Psychology: An International Review, 51, 355-387. http://doi.org/doi.org/10.1111/1464-0597.00951

West, M. A., \& Anderson, N. R. (1996). Innovation in top management teams. Journal of Applied Psychology, 81, 680-693. http://doi.org/10.1037/0021-9010.81.6.680

West, M. A., \& Farr, J. L. (1990). Innovation at work. In M. A. West \& J. L. Farr (Eds.), Innovation and creativity at work: Psychological and organizational strategies (pp. 3-13). Chichester: Wiley.

West, M. A., Hirst, G., Richter, A., \& Shipton, H. (2004). Twelve steps to heaven: Successfully managing change through developing innovative teams. European Journal of Work and Organizational Psychology, 13, 269-299. http://doi.org/10.1080/13594320444000092

World Bank. (2019). World Development Report 2019: The Changing Nature of Work. Washington, DC: World Bank. http://doi.org/10.1596/978-1-4648-1328-3 
Zacher, H., \& Rosing, K. (2015). Ambidextrous leadership and team innovation. Leadership and Organization Development Journal, 36, 54-68. http://doi.org/10.1108/LODJ-11-2012-0141 
Table1

Correlations, Means and Standard Deviations of the Study Variables

\begin{tabular}{|c|c|c|c|c|c|c|c|c|c|c|c|c|c|}
\hline & $M$ & $S D$ & 1 & 2 & 3 & 4 & 5 & 6 & 7 & 8 & 9 & 10 & 11 \\
\hline 1. Extraversion $M$ & 3.54 & 0.30 & - & & & & & & & & & & \\
\hline 2. Extraversion $S D$ & 0.52 & 0.16 & -.48 & - & & & & & & & & & \\
\hline 3. Agreeableness $M$ & 3.06 & 0.28 & .22 & -.08 & - & & & & & & & & \\
\hline 4. Agreeableness $S D$ & 0.52 & 0.12 & -.15 & .35 & -.09 & - & & & & & & & \\
\hline 5. Openness $M$ & 3.42 & 0.33 & -.23 & .13 & -.08 & .15 & - & & & & & & \\
\hline 6. Openness $S D$ & 0.58 & 0.16 & -.02 & .08 & -.06 & .40 & .20 & - & & & & & \\
\hline $\begin{array}{l}7 . \\
\text { Conscientiousness } \\
M\end{array}$ & 3.39 & 0.21 & .27 & -.39 & -.12 & -.12 & -.17 & -.13 & - & & & & \\
\hline $\begin{array}{l}8 . \\
\text { Conscientiousness } \\
S D\end{array}$ & 0.63 & 0.20 & -.33 & .02 & -.20 & -.03 & .10 & .12 & .01 & - & & & \\
\hline $\begin{array}{l}\text { 9. Team innovation } \\
\mathrm{T} 1\end{array}$ & 5.29 & 0.43 & .07 & -.36 & -.02 & -.13 & .04 & .00 & .50 & -.24 & - & & \\
\hline $\begin{array}{l}\text { 10. Team innovation } \\
\mathrm{T} 2\end{array}$ & 5.17 & 0.40 & .13 & -.49 & .07 & .01 & -.09 & .14 & .15 & -.15 & .47 & - & \\
\hline $\begin{array}{l}\text { 11. Team innovation } \\
\mathrm{T} 3\end{array}$ & 5.11 & 0.44 & .04 & -.58 & -.07 & -.04 & -.16 & -.10 & .23 & -.10 & .62 & .78 & - \\
\hline
\end{tabular}

Note. $N=32$. Teams. $\mathrm{T} 1=$ Time $1, \mathrm{~T} 2=$ Time $2, \mathrm{~T} 3=$ Time 3 . Correlations of $|\mathrm{r}| \geq .35$ are significant at $p<.05$. 
Table 2

Multilevel Growth Model Predicting Changes in Team Innovation from Team Personality and Team Personality Composition

\begin{tabular}{|c|c|c|c|c|c|}
\hline Value & $\gamma$ & $S E$ & $d f$ & $t$ & $\gamma_{s}$ \\
\hline Intercept & 5.19 & 0.05 & 32.00 & $111.80^{* * *}$ & .00 \\
\hline Time & -0.09 & 0.03 & 62.70 & $-3.38 * *$ & -.22 \\
\hline Extraversion (EX) $M$ & -0.13 & 0.06 & 32.00 & $-2.34 *$ & -.33 \\
\hline Agreeableness (A) $M$ & 0.00 & 0.05 & 32.00 & -0.06 & -.01 \\
\hline Openness (O) $M$ & -0.02 & 0.05 & 32.00 & -0.37 & -.04 \\
\hline Conscientiousness (C) $M$ & 0.07 & 0.05 & 32.00 & -1.37 & .17 \\
\hline EX $S D$ & -0.25 & 0.06 & 32.00 & $-4.18 * * *$ & -.58 \\
\hline A $S D$ & 0.04 & 0.05 & 32.00 & 0.69 & .09 \\
\hline O $S D$ & 0.03 & 0.05 & 32.00 & 0.64 & .08 \\
\hline C $S D$ & -0.11 & 0.05 & 32.00 & $-2.17 *$ & -.26 \\
\hline Time $\times \mathrm{E} M$ & -0.01 & 0.03 & 62.70 & -0.49 & -.04 \\
\hline Time $\times \mathrm{A} M$ & -0.02 & 0.03 & 62.70 & -0.83 & -.06 \\
\hline Time $\times \mathrm{O} M$ & -0.06 & 0.03 & 62.70 & -1.95 & -.13 \\
\hline Time $\times \mathrm{C} M$ & -0.11 & 0.03 & 62.70 & $-3.41 * *$ & -.25 \\
\hline Time $\times \operatorname{EX} S D$ & -0.11 & 0.03 & 62.70 & $-3.28 * *$ & -.27 \\
\hline Time $\times \mathrm{A} S D$ & 0.07 & 0.03 & 62.70 & $2.15^{*}$ & .16 \\
\hline Time $\times$ O $S D$ & -0.05 & 0.03 & 62.70 & -1.59 & -.11 \\
\hline Time $\times \mathrm{C} S D$ & 0.04 & 0.03 & 62.70 & 1.17 & .08 \\
\hline \multicolumn{6}{|l|}{ Variance components } \\
\hline Group & 0.052 & & & & 0.292 \\
\hline Group slope & 0.00006 & & & & 0.0003 \\
\hline $\mathrm{COV}_{\text {group, group slope }}$ & 0.002 & & & & 0.101 \\
\hline Residual & 0.049 & & & & 0.275 \\
\hline Log-likelihood & -13.40 & & & & -97.10 \\
\hline Overall $R^{2}$ & 0.44 & & & & \\
\hline
\end{tabular}

Note. $N=32$ Teams measured at $k=96$ measurement occasions. Time was centered at Time 2 such that main effects indicate the situation midway through the data collection. $R^{2}$ was calculated using the marginal $R^{2}$-formula in Nakagawa and Schielzeth (2013) and captures the overall amount of variance explained by the fixed-effects predictors (personality and time). 


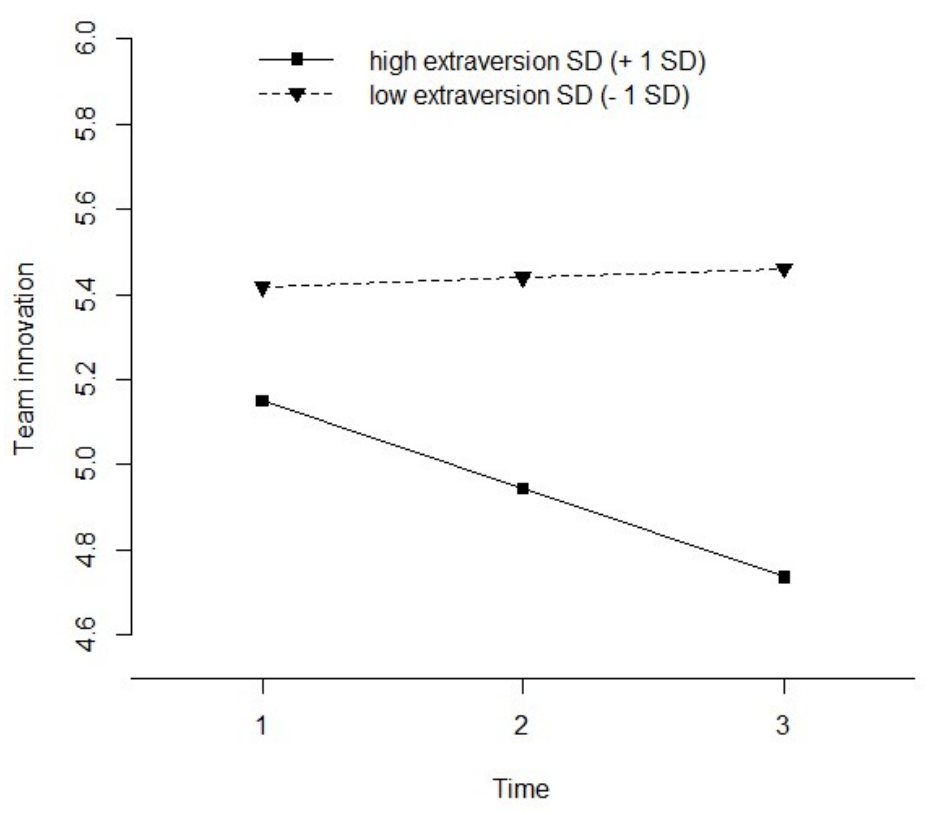

Figure 1. Development of team innovation over time in teams with high and with low variability in extraversion. Values are predicted values from the multilevel growth model presented in Table 2. 


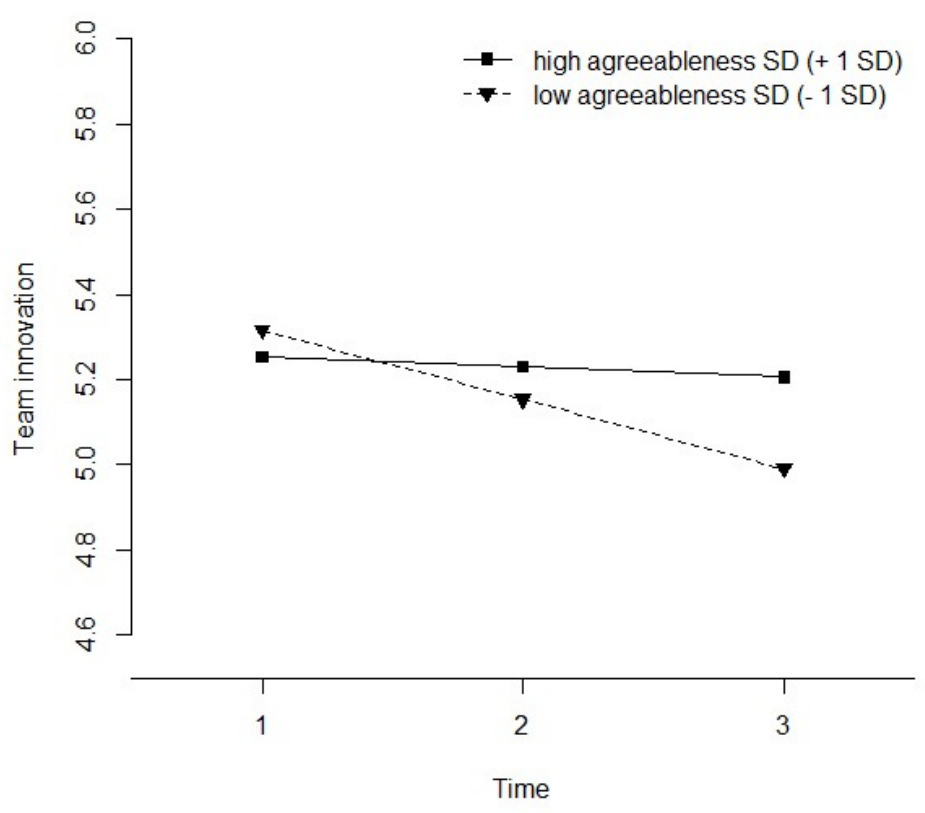

Figure 2. Development of team innovation over time in teams with high and with low variability in agreeableness. Values are predicted values from the multilevel growth model presented in Table 2. 


\section{Appendix A}

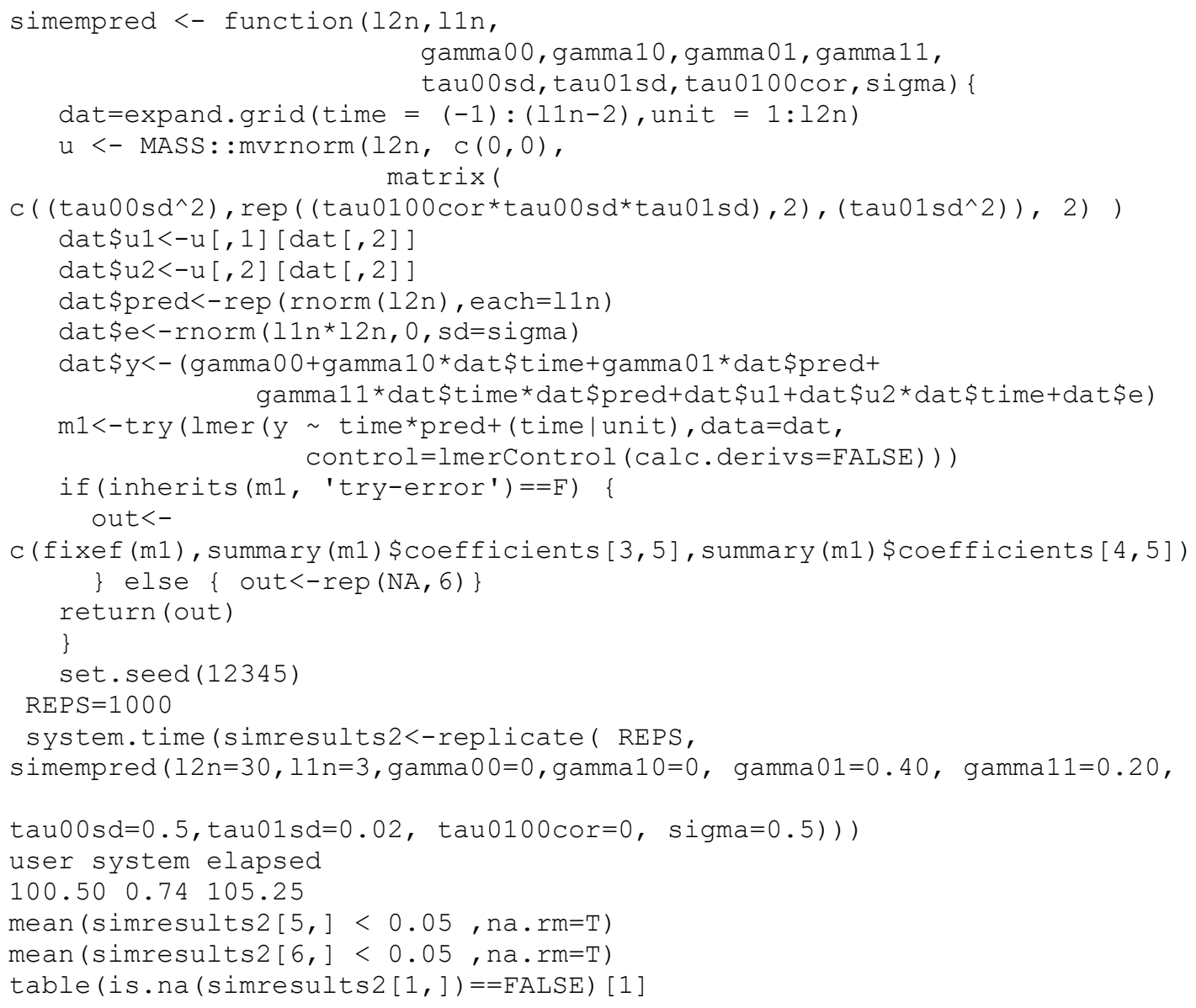




\section{Author bio's}

Sophie den Hartog is a doctoral student at the Department of Personnel Management, Work and Organizational Psychology at Ghent University, Belgium. Her research focuses on personality, innovation and organizational behavior.

Malte Runge is a doctoral student at the Department of Personnel Management, Work and Organizational Psychology at Ghent University, Belgium. His research focusses on individual differences in organizational behavior, implicit motivation and assessment.

Gudrun Reindl is a doctoral student at the Department of Personnel Management, Work and Organizational Psychology at Ghent University, Belgium. Her research focuses on work events, personality, and diary methods.

Jonas W. B. Lang is an associate professor in the Department of Personnel Management, Work and Organizational Psychology at Ghent University, Belgium. His current research interests focus on multilevel models, item-response theory, adaptability, cognitive abilities, and implicit motivation. 